\title{
Motor Bus vs. Street Car
}

\section{Some of the Reasons Why the Truck Is Doing So Well in This Competition By R. E. Fulton}

I $N$ a consideration of the reasons for the growing 1 acceptance of the motor bus as an economic necessity in passenger transportation, it is well first to examine the ultimate effect of increases in population upon traffic facilities. While the necessity for immediate action to solve serious congestion problems is now being felt only by the larger cities, the requirements of smaller cities and their future development deserve just as much consideration to prevent this congestion in years to come.

It is evident that the traction lines are becoming more and more inadequate to handle the congestion that is increasing every dav. Since the amount of traffic they will hold is limited by the tracks on which they run, it will be impossible for them to keep up with the growing needs of transportation unless new tracks are laid. This, however, is prohibited by the increasing congestion of privately owned vehicles on the highways. Increasing population on the one hand demands more public transportation facilities. The increasing number of privately owned passenger and commercial vehicles on the other hand demands better highway facilities. Can one factor be satisfied except at the expense of the other?

The present serious financial condition of these public utility corporations throughout the country is bound to mean increased fares, and the burden imposed upon them by increasing population is bound to mean more and more congestion. The motor bus will not only solve the serious traffic problem, but will provide the public with a more flexible satisfactory mode of transportation at a lower cost.

In the majority of large cities it is out of the question to lay more tracks for surface car lines in thickly populated business and residential sections-there is no room for them. In view of this fact it is only logical to assume that motor buses will be used to relieve the congestion, as they are free to operate on any route without tracks. And it is very possible that the time will come when traffic will have increased to such an extent that the streets will seem unable to hold it In this event the only solution would be the discontinuance of surface car lines and the substitution of motor busses. This for the simple reason that busse neither block the highways nor are easily blocked, being flexible and able to move about in traffic. Surface cars, on the other hand, do block traffic and are easily tied up themselves by a block.

As far as less thickly populated sections are concerned there is every reason to believe that future development of transportation facilities will favor the motor bus. The laying of tracks for a surface car line represents a huge initial expense for right of way, bridges, grading and rails. If such a line does not prove profitable, it cannot be diverted. The flexibility of the motor bus system, however, does not confine it to any one fixed route.

Public utility corporations everywhere are gradually losing the faith of investors. Their inability to in crease fares to keep up with increasing costs of operation considerably decreases their dividends. In view of this, it is becoming increasingly difficult to find investors who will lend the money to build and equip new traction lines, while far better inducements are offered in other securities.

Efficiency and economy of operation are in favor of the motor bus. These economies are principally due to the fact that the tremendous overhead expenses of the surface car lines are eliminated in the operation of. motor busses. The bus is its own power plant and it consumes power only when in operation. Since it is speedier than the surface car, a bus can make more trips per day thereby increasing the revenue per unit of expenditure.

Motor bus routes offer many conveniences that cannot be offered by traction lines. Another point-they unload passengers at the curb which is much safer. In case of a blockade, a bus can detour. This fact alone works as a benefit in two ways-it makes a more dependable transportation system and tends to relieve the congestion incidental to blockades. Not being confined to tracks, busses can receive and discharge passengers nearer to their homes. Then, too, we have the obvious fact that people would rather ride in a motor bus not only because of its conveniences but because of the suggestion it conveys of pleasurable outdoors.

The motor bus is also a big factor in solving the industrial labor problem. Factory sites within city limits where labor is available, are scarce. The use of busses to carry employees to outlying sections where sites are obtainable is gradually being recognized as the logical solution to the problem.

A short time ago a party of ladies left Easton, Pa. in a pneumatic tired motor bus to attend a matinee theater performance in New York City, a distance of 73 miles by train. They left in the morning, arrived in plenty of time for the matinee and returned to their homes in the bus that same evening. Such illustrations of the potentialities of the motor bus make it easy to conceive the time when commuters will travel to business in busses more quickly and comfortably than by means of suburban trains. Metal laid roads designed for one-way motor traffic with no speed limit re inevitable.

All through the development of passenger transporta tion in every section, from the large city to the rural community, the motor bus will be felt more and more as the years go by

\section{Correspondence}

The editors are not responsible for statements made in the correspondence column. Anonymous communications cannot be considered, but the names of correspondents will be withheld when so desired.

\section{Bombardments from the Skies}

To the Editor of the Scientific American:

In the article under the above title in your issue of December 13, it is stated that " $A$ body of matter entering the earth's atmosphere from outer space is intensely heated at its surface by the friction of the air, and hence becomes luminous."

Is it not possible that the meteor, consisting of iron or a large percentage of iron, of exceptional purity and of high electrical conductivity, is heated to incandescence by the heavy electrical currents induced in the body of the meteor caused by its entering the earth's magnetic field at terrific velocity?

Could the atmosphere be dense enough at the altitude where meteors are first seen to cause the amount of friction necessary to make luminous the amount of matter contained in some meteors that have reached the earth's surface?

It is possible that both the air friction and the eddy currents combine to produce the phenomena. Again: If the crater at Canyon Diablo, Ariz., had been made by the impact of a meteorite, would not it have been vaporized when striking the earth, leaving no traces except where some of the edges of the body were broken off when first entering the earth's crust

The writer has made some interesting experiments upon high-velocity bodies; among these was the firing of lead bullets from a high-power rifle through $3 / 8$-inch boiler steel, the rifle used was of .22 caliber of a well-known make, using a cartridge which gave a niuzzle velocity of 2,800 feet per second.

The copper jacket on the projectile was usually left in the hole made by the bullet, a piece of timber placed 6 inches back of the steel plate usually showed no signs of the impact of the bullet or any part of it, which seemed to indicate that the bullet was vaporized in passing through the plate. Have we not here an exact analogy of the meteor crater?

Clemmons, N. C.

\section{The Rotary Bevel Shear}

\section{To the Editor of the ScirvTIrIC}

In your November 8 th issue on page 464 , under the subject of "Inventions New and Interesting. a department devoted to pioneer work in the Arts," you illustrate and describe an electric notary bevel shear. We respectfully wish to call your attention to the fact that the particular machine which is shown in your publication was not originally developed at Wilmington, Del., and we would appreciate greatly if you would revise your statements

For your information, the rotary bevel shear for the bevel shearing of plates and angles was originally designed and developed at Marshalltown, Iowa, back in the year 1892. Two types of rotary bevel shears were built. One was designed with parallel drivingshafts on which were mounted the cutting blades. There also was a machine accomplishing the same work, but the. lower cutter shaft was on a horizontal plane.

Later we purchased this property, which included buildings, patents, good will, etc. At the expination of the bevel shear patents, which originally were in the name of David Lennox, the Wilmington, Del., concern put on the market a duplicate of our Lennox machine.

In 1915 we improved the design of the machine by doing away with the nut holding attachment on the upper blade, to bring the machine within the reach of close bevel shearing work on angles, for which there was considerable call. The new design of holding the blades was by recess screws, and the general principle was patented, which patent this company now controls, and of which we claim the Wilmington mode is an infringement. Joseph T. RYerson \& SoN. Chricago.

\section{High Temperatures}

To the Editor of the ScIENTIFIC AMERICAN :

It has usually been assumed that the highest attainable temperature is obtained from the electric arc

We are all familiar with the burning glass and the grea't concentration of heat possible with it. Large burning glasses would be impracticable to make and would have excessive heat absorption.

However, by using a large parabolic reflecting mirror directed at the sun, the concentration of heat at the focus, would seen to be-limited only by the size of the mirror, the accuracy of its surface, and the insulation of the impingent body. Temperatures equal to or far higher than those of an arc are easily obtained. In an experiment in which the writer was interested at the Marine Searchlight Battalion, Philadelphia Navy Yard, a 60-inch paralbolic glass mirnor was directed at the sun: a one-half-inch steel bar held in the focus was melted in a few seconds; similar results occurred with a 1/2-inch asbestos board.

Assuming incident radiant energy of 5 B.t.u pro square foot per minute, and a mirror reflection of 85 per cent, there was about 1.8 horse-power concentrated on approximately .01 square inches section area of the focus in the above case. This would be at least four times the concentration of power as compared with the crater area of an arc of similar power.

The heat is potential, that is, unless there is an object at the focus for the rays to impinge on, the rays will merely cross and pass on.

It would appear that there could be experimental and commercial utilization of such a convenient source of high temperatures.

W. J. Platten.

Green Bay, Wis.

\section{Quinoa}

To the Editor of the ScIEntific American:

When quinoa has been developed into the wonderful breakfast food which Burbank and A. I. Root predict, I hope that someone takes the trouble to teach the Peruvian Indians how to cook it. I had to eat it daily for weeks when in the Andes and it was not well flavored nor even palatable. H. GuLICK.

Gwalior, India.

\section{The Steam Car}

To the Editor of the ScIentific American:

The improvements suggested for steam cars by your correspondent's letter in a recent issue are ideal if practical. Given a device as simple and dependable as the ordinary gage glass for positively indicating the true water level in the boiler, and place the pumps where they would be readily accessible and further improvements could be dispensed with, still leaving the "steamer" the logical car of the future and the most desirable at present

The fundamental principles involved in the combustion of oils renders it unlikely that burners can be improved, to any extent, over present forms. I have had, perhaps, more trouble with "the fire" than Mr. Stanley ever intended to impose upon the sum total of his customers only to find, in the end, that 99 per cent of fault was my own, and I claim to be an oil fireman at that. 